\begin{tabular}{|c|c|c|}
\hline PKS & Revista de GEOGRAFIA & OJS \\
\hline $\begin{array}{l}\text { PUBLIC } \\
\text { KNOWLEDGE } \\
\text { PROJECT }\end{array}$ & $\begin{array}{c}\text { (RECIFE) } \\
\text { http://www.revista.ufpe.br/revistageografia }\end{array}$ & $\begin{array}{l}\text { OPEN } \\
\text { JOURNAL } \\
\text { SYSTEMS }\end{array}$ \\
\hline
\end{tabular}

\title{
POSSIBILIDADES E DESAFIOS PARA PRÁTICA DOCENTE NO PROCESSO DE APRENDIZADO DISCENTE E O USO DAS NOVAS TECNOLOGIAS DA INFORMAÇÃO E COMUNICAÇÃO (NTIC) NO ENSINO DE GEOGRAFIA
}

\author{
Luiz Carlos Prazeres Serpa Alfino ${ }^{1}$, Francisco Kennedy Silva Santos ${ }^{2}$ \\ ${ }^{1}$ Doutorando em Geografia na Universidade Federal de Pernambuco. Email: lcserpa2000@yahoo.com.br \\ 2 Professor no Departamento de Geografia da Universidade Federal de Pernambuco. Email: \\ kennedyufpe@gmail.com
}

Artigo recebido em 16/03/2017 e aceito em 21/06/2017

\begin{abstract}
RESUMO
O presente texto tem o proposito de discutir o uso das Novas Tecnologias da Informação e Comunicação (NTIC) como campo de possibilidades para a mediação pedagógica no ensino de Geografia e para construção de aprendizagens significativas, tendo como objetivo central desvelar no cenário da docência atual qual o 'lugar' das NTIC no trabalho docente. Neste primeiro momento, nos deparamos com as pesquisas do tipo "estado da arte" ou "estado do conhecimento" de caráter bibliográfico para dar suporte a nossas intervenções. As questões suscitadas nesta primeira fase da pesquisa levantam discussões a cerca de como as NTIC contribuem para promover a construção e a mobilização de saberes para o mundo do trabalho e aparecem como desafio para mediação da prática docente.
\end{abstract}

Palavras-chaves: Ensino de geografia. Mediação pedagógica. Prática docente. Novas tecnologias. Formação docente.

\section{POSSIBILITIES AND CHALLENGES FOR TEACHING PRACTICE IN LEARNING PROCESS STUDENT AND THE USE OF NEW TECHNOLOGIES OF INFORMATION AND COMMUNICATION (ICT) IN GEOGRAPHY TEACHING}

\begin{abstract}
This article has the purpose of discussing the use of New Information and Communication Technologies (ICT) as a field of possibilities for mediation in teaching Geography and building meaningful learning, with a main objective to unveil in the current teaching scenario which the 'place' of NICT in teaching. At first, we encounter the type research "state of art" or "state of knowledge" of bibliographic to support our interventions. The issues raised in this first phase of the research raise discussions about how NTIC help to promote the construction and mobilization of knowledge for the world of work and appear as a challenge for the teaching practice mediation. Keywords: Geography teaching. Pedagogical mediation. Teaching practice. New technologies. teacher training.
\end{abstract}




\section{PRIMEIRA APROXIMAÇÃO}

Diante do atual cenário do desenvolvimento científico e tecnológico, nos deparamos com novas inquietações no campo da racionalidade técnica e pedagógica, que funcionam como mecanismos determinantes para a docência. Partimos, portanto, da necessidade de compreender em que medida a inserção de Novas Tecnologias da Informação e Comunicação (NTIC) no ensino, em especial na educação básica, constituiu-se, para professores de Geografia, como mediação pedagógica para a construção e mobilização de saberes.

Entender os princípios formativos que subsidiam o uso das Tecnologias da Informação e Comunicação (TIC) e como ela chega no "chão da sala de aula", permitirá a construção de referenciais para orientar uma proposta de metodologia para o uso destas tecnologias, dando sentido ao "uso" enquanto dispositivo didático-pedagógico e contrariando a ideia de que o "uso" de tecnologia é arbitrário.

Ademais, subjacente a esses entendimentos encontra-se a preocupação de alargar o raio das investigações que tratam das TIC como mediadora da apreensão e da percepção dos alunos acerca dos conceitos geográficos e sua intrínseca relação com os demais componentes curriculares, elemento indispensável à formulação do saber, das descobertas, como atividade intencional e inseparável dos objetivos da vida escolar. Além do que, apresenta-se como oportunidade de aproximação e colaboração interinstitucional entre pesquisadores experientes e iniciantes, e, também, contribui para o reconhecimento da importância do professor da educação básica e do uso e apropriação situada das NTIC como mediadora da prática docente e da pesquisa no espaço da formação.

Essa produção constitui desdobramentos dos primeiros resultados da pesquisa intitulada Impacto das Novas Tecnologias da Informação e Comunicação (NTIC) sobre o trabalho docente dos professores e das suas práticas pedagógicas no ensino de geografia da rede pública estadual de Pernambuco, apoiada pelo Conselho Nacional de Desenvolvimento Científico e Tecnológico - CNPQ, por meio da Chamada: MCTI/CNPQ/Universal 14/2014.

A proposta insere-se no campo das investigações que elegem o ensino e a pesquisa como categorias fundantes para identificar e compreender as práticas pedagógicas desenvolvidas pelos professores da educação básica e que em situação de trabalho elegem a pesquisa como princípio formativo para a produção de novos conhecimentos e de aprendizagens significativas por meio do uso das NTIC. A proposta apresenta como objetivo central compreender melhor a mudança operada no trabalho docente dos professores de 
Geografia da educação básica, confrontados com as NTIC, no plano de suas representações diante da integração das NTIC no ensino de geografia, de suas atitudes diante desse novo modo de mediação pedagógica, de suas práticas pedagógicas na sala de aula para formação dos conceitos geográficos.

Partimos, portanto, neste primeiro momento de uma análise auto-reflexiva do 'lugar' das NTIC no trabalho docente, respaldados em pesquisas tipo "estado da arte" ou "estado do conhecimento" de caráter bibliográfico para dar suporte a nossas intervenções (BRZEZINSKI e GARRIDO, 1999; FERREIRA, 2002). A realização de estados da arte possibilita a efetivação de balanço da pesquisa de uma determinada área de conhecimento e podem significar uma contribuição importante na constituição de seu campo teórico, pois procuram identificar os aportes significativos da construção da teoria e prática, elucidando as possíveis lacunas e ao mesmo tempo revelando experiências inovadoras investigadas que apontem alternativas de solução para os problemas da prática e reconhecimento das contribuições da pesquisa na constituição de propostas na área focalizada.

Compreender como os professores de Geografia da educação básica concebem o ensino e o uso de novas tecnologias é uma pista para evidenciarmos tramas temporais da atualidade, como é o caso de uma efetiva prática docente pautada no conhecimento e no desenvolvimento de habilidades e competências para o mundo do trabalho e para inserção social. Acrescenta-se ainda que o trabalho por meio destes recursos nos permite inferir que o aumento nos padrões de escolaridade não está dissociado de uma política pública de formação efetiva que seja orientada pelo onde e como utilizar as NTIC nos espaços escolares.

É no caminho reflexivo-crítico, trilhado por essas inquietações, que procuramos neste artigo desenvolver uma breve análise dos saberes docentes mobilizados no âmbito do trabalho dos professores de Geografia como profissionais reflexivos, com ponderações na construção do pensamento geográfico ao longo do tempo, tendo como referencial a prática docente e o desafio de compreender o uso das novas tecnologias da informação e comunicação, como ferramentas de uma mediação pedagógica no ensino das Ciências Geográficas.

\section{A EDUCAÇÃo GEOGRÁFICA E SEUS APORTES EPISTEMOLÓGICOS: TRAÇANDO UM CENÁRIO}

A dinâmica das Ciências Geográficas permite interagir com diversos saberes e campos de estudo. No entanto, ainda hoje, há diversas discussões a cerca do objeto da 
Geografia, cuja temática tem sido fruto de um constante debate com muitas definições sendo aceitas ou rejeitadas, refletidas historicamente na linha temporal do pensamento geográfico.

Sem qualquer intuito de aprofundar tal discussão, mas ao mesmo tempo apresentar determinadas acepções mais aceitas, Moraes (2005) expõe algumas das múltiplas definições do objeto da Geografia que se encontram presentes em muitos dos debates acadêmicos. Essas definições têm variado entre diversos estudiosos no assunto, cada um buscando fundamentar as especificidades que as determinam.

Há milhares de anos o homem utilizou a contemplação da natureza para construir formas de percepção de sua dinâmica, a fim de compreender sua realidade e atender suas necessidades, estabelecendo instrumentos de análise e de conhecimento sobre o meio. Uma relação entre o sujeito e o objeto, onde o primeiro busca desvelar o segundo.

Desse modo, a relação homem-natureza foi produzindo ao longo do tempo diferentes tipos de conhecimentos. Desde o conhecimento tido como vulgar ou popular, cujas estruturas encontravam-se no senso comum, na espontaneidade, na práxis da vida cotidiana, ao conhecimento filosófico, teológico e científico. Este último, fundamentado a partir de métodos e técnicas, fruto da investigação científica que, para a Geografia, veio aflorar nos idos do século XIX, com as contribuições dos estudos de Alexander von Humboldt (17691859) e Karl Ritter (1779-1859).

Com esses estudiosos a Geografia passa a ter um caráter sistemático e metodológico dentro da análise da ciência moderna. Para Humboldt, a Geografia é entendida "como a parte terrestre da ciência do cosmo, isto é, como uma espécie de síntese de todos os conhecimentos relativos à Terra" (MORAES, 2005, p. 62).

Ao se dispor em avaliar os fatos, o autor percebe que estes deveriam ser analisados em suas conexões, buscando estabelecer uma relação de causa e efeito. A partir dessa analogia, tem-se o Princípio da Causalidade, pois, segundo Humboldt, "a causalidade introduz a unidade entre o mundo sensível e o mundo do intelecto". Ou seja, traz em seu bojo uma associação do conhecimento científico e filosófico na Geografia.

Para Ritter, a Geografia é entendida como um estudo dos lugares centralizado no homem, na individualidade regional, em uma análise antropocêntrica, apreciando a relação homem-natureza.

Esses autores encontram-se movidos por um fundo holístico, uma força da organização na espacialidade, na comunhão entre subjetividade e objetividade, na 
conformação entre o todo e a parte, na ligação estético-teleológica na consideração da natureza.

No transcurso do século XIX ao XX encontramos uma Geografia muito próxima das questões nacionais. Um momento em que a Europa encontra-se passando por uma reconfiguração geopolítica, com a formação de alguns Estados Nacionais com seus arsenais industriais em ascensão, motivados pela política capitalista expansionista do neo-colonialismo (1875-1914), voltada para o escoamento da produção industrial para a América Latina e a conquista de territórios no continente africano e asiático. Nesse contexto, tem-se o advento da Primeira Guerra Mundial (1914-1918), resultado da explosão da nova fase do capitalismo mundial, mais conhecido como Imperialismo.

É nesse cenário que se encontra o tempo das escolas nacionais da Geografia moderna (séculos XIX-XX), onde se tem em relevo a ampliação do conhecimento geográfico para outros níveis de ensino, passando pelo primário e secundário, chegando às cátedras universitárias, com evidências de estudos voltados tanto para a Geografia Humana (com questões relacionadas ao estudo da diferenciação regional da terra; questões relacionadas aos grupos humanos e do ambiente e sua problemática regional e o estudo das paisagens), como para a Geografia Física, ao retratar questões do ponto de vista ecológico e nos estudos temáticos como geomorfologia, geologia, climatologia, entre outros (CLAVAL, 2006).

Foi nesse contexto, quando o darwinismo se expandia na Europa, com os estudos sobre a seleção natural e as relações entre homem e natureza e os efeitos do ambiente sobre o homem, que surgiu a escola alemã, marcada pela concepção determinista na Geografia, por Friedrich Ratzel (1844-1904), no momento em que a Alemanha ainda não existia enquanto Estado Nacional, mas que se encontrava em vias de formação (1871), e que teve no discurso geográfico, um sentimento nacionalista motivado por uma identidade territorial. Nessa conjuntura, o conhecimento da Geografia tornou-se um instrumento propulsor para difundir os ideais nacionalistas do povo alemão, contribuindo para a integração de seu território.

Embora bastante ativa ao longo do século XIX, a Geografia francesa, contemporânea à concepção determinista da escola alemã, torna-se mais sólida ao final do referido século, principalmente, pelos estudos de Elisée Reclus (1830-1905) e Vidal de La Blache (18451918). O primeiro, ainda que sensível às questões da natureza dá ênfase aos estudos sobre as cidades, à diversidade de povoamento e à grandeza cultural da Geografia. O segundo contribuiu para o desenvolvimento da escola francesa, que veio a se consolidar no decorrer da primeira década do século XX, ao expandir-se nos estudos acadêmicos (CLAVAL, 2006). 
Com La Blache a França tornou-se o centro das grandes discussões das ciências geográficas. Critica a escola alemã de Ratzel, nas suas formulações naturalistas - onde o homem é concebido como (não social), mas biológico. Desse modo, o homem encontra-se submisso ao meio natural ou torna-se produto deste. Em La Blache, o homem encontra-se em uma multiplicidade de ações/decisões diante das possibilidades que lhes são proporcionadas pela natureza. Dessa forma, apresenta em seus estudos uma análise em que o objeto da Geografia encontra-se na relação homem-natureza sob a expectativa da paisagem.

De modo geral, a escola francesa não era constituída de uma única percepção epistemológica da Geografia. Seus mestres, embora conservadores e estruturados em uma concepção ideológica, tinham em seus discursos a defesa da neutralidade científica. No entanto, seus estudos apresentavam como ponto de convergência a predominância de questões sobre a paisagem e a região.

$\mathrm{Na}$ Geografia americana tiveram de início duas escolas consagradas, a do Middle West, "preocupada pelo rigor nos procedimentos de recolha de dados, [...] e de encontrar explicações funcionais para as distribuições observadas", com destaque para os estudos da Geografia econômica e da Geografia política, com Richard Hartshorne (1899-1992). E a escola de Berkeley, com ênfase nos estudos da ecologia cultural, desenvolvidos por Carl Sauer (1889-1975) (CLAVAL, 2006, p. 96).

Com Hartshorne novas reflexões sobre a cientificidade da natureza geográfica são desenvolvidas, a partir das análises feitas sobre a evolução do pensamento geográfico e de sua revisão, com a publicação de "dois livros: A natureza da geografia, publicado em 1939; [...] e Questões sobre natureza da geografia, publicado em 1959” (RODRIGUES, 2008, p. 94).

A partir dos anos 1950, a Geografia tomou impulso no mundo anglo-saxônico, provavelmente motivada pela necessidade de superação dos períodos de crise políticoeconômica no sistema capitalista mundial, emergindo estudos da econometria e da economia positiva, intensificando avanços científicos, econômicos e tecnológicos que alavancaram a antiga potência hegemônica do século XIX - A Inglaterra - e a atual potência hegemônica do século XX - Os Estados Unidos, onde o método quantitativo e o recorte dos dados estatísticos passam a redesenhar a análise dos estudos geográficos. Vale salientar que, a Nova Geografia, também fez uso da abordagem sistêmica nos estudos geográficos, buscando um maior desenvolvimento no delineamento de suas pesquisas.

Os autores até aqui trabalhados fazem parte do grande número de estudiosos referenciados na Geografia Moderna, os quais não poderiam deixar de ser apresentados em 
nosso trabalho, mesmo que ao nível de "breves reflexões epistemológicas", pois eles constituíram a base do pensamento geográfico na modernidade. No entanto, a temática aqui trabalhada requer uma análise da NTIC, reportando a períodos a partir dos anos 1970. Dessa forma, será a partir dos anos 70 do século XX, com a chamada Geografia Crítica que passaremos a refletir.

Inspirada nas análises de filósofos marxistas, principalmente, franceses. A Geografia Crítica debruça o seu olhar para o estudo do espaço, para as experiências compartilhadas no espaço das ações humanas, nos estudos da pobreza, da exploração, da desigualdade, da justiça social, da forma de produzir e distribuir as riquezas, do trabalho e em todas as contradições do fazer humano, e na forma como os homens passam a registrar a sua existência.

A Geografia Crítica passa a ser entendida, dentro das ciências geográficas, como uma 'voz' que denuncia as contradições existentes na realidade espacial. Um espaço que passa a ser estudado por meio de quatro categorias: forma, função, estrutura e processo, que segundo Santos (1998) são quatro termos disjuntivos, mas associados, a empregar segundo um contexto do mundo de todo dia. Tomados individualmente representam apenas realidades parciais, limitadas, do mundo. Considerados em conjunto, porém, e relacionados entre si, eles constroem uma base teórica e metodológica a partir da qual podemos discutir os fenômenos espaciais em totalidade.

Portanto, é a partir dessa captação de uma Geografia preocupada com o espaço social, enquanto objeto de estudo, que nosso trabalho busca subsidiar sua importância para a compreensão da prática docente, assumindo, também, um papel instrumental de ação transformadora da ordem social que, a partir de uma abordagem dialética, tem atuado em cenários cada vez mais complexos e dinâmicos da sociedade, com o uso das novas tecnologias da informação e comunicação - NTIC.

As mudanças sociais no mundo do trabalho e da vida desde os anos de 1980 levaram inevitavelmente a uma "crise" do paradigma do conhecimento tradicional, "tecnocrata" e "behaviorista" que durante muitos anos dominou mundialmente a construção de planos de ensino e currículos das escolas.

Os processos sociais de modernização geram uma mudança de paradigma, ou até mesmo uma ampliação do conhecimento no trabalho, que teve seu reflexo na sociedade "taylorizada" na rígida divisão do planejamento e da execução do trabalho e da separação rígida entre educação (teórica) geral e formação (prática) profissional. Assim devemos substituir o conceito tradicional de conhecimentos e de saberes pela visão de competência, 
que não deverá ter somente uma conotação funcionalista em relação às mudanças sociais e laborais, mas, sendo "essencialmente política", orienta-se à capacidade subjetiva de poder intervir e transformar estruturas tradicionais no trabalho e na vida social (THERRIEN, 1998).

\section{NOVAS TECNOLOGIAS: CONSUMO E IMPORTÂNCIA DE SUA CONVERGÊNCIA PARA O ENSINO E A APRENDIZAGEM}

A discussão atual sobre as novas competências no trabalho e na vida demonstra ainda uma grande incerteza sobre as suas fundamentações teórico-metodológicas e práticopedagógicas, o que repercute diretamente sobre o entendimento de que seus objetivos venham a ser emancipatórios ou somente instrumentais. Todavia, em muitos países, profundas reformas educacionais introduzem uma concepção de aprendizagem, ensino e formação sob o ângulo das competências. No Brasil a formação inicial de professores para a educação básica, por exemplo, passa atualmente por uma profunda reforma e o papel dos professores formadores de futuros professores tende a ser consideravelmente modificado, considerando a introdução das NTIC.

Inspirada na expressão cunhada por Lévy (1993) - "arquitetos cognitivos" -, Ramal (2002, p. 191) delineia o perfil do profissional para atuar no campo educacional, frente à demanda pela incorporação das tecnologias e das mídias:

O arquiteto cognitivo: (a) é um profissional; (b) capaz de traçar estratégias e mapas de navegação que permitam ao aluno empreender, de forma autônoma e integrada, os próprios caminhos da construção do (hiper) conhecimento em rede; (c) assumindo, para isso, uma postura consciente de reflexão-na-ação; e (d) fazendo uso crítico das tecnologias como novos ambientes de aprendizagem.

Masetto (2000, p. 133) problematiza o uso da tecnologia como mediação pedagógica no processo de aprendizagem, começando pelo fato de que, por muito tempo, acreditou-se que educar significava transmissão de conhecimento organizado e sistematizado de diversas áreas e exigência de memorização e reprodução de informações (nas provas). Decorrente dessa visão, o autor aponta o fato de que, nos cursos de formação de professores, "[...] percebe-se por parte dos alunos a valorização do domínio de conteúdo nas áreas específicas em detrimento das disciplinas pedagógicas" (MASETTO, 2000, p. 134). 
Vale acrescentar que esse desprestígio às disciplinas pedagógicas é reforçado quando não incitado - por muitos professores nos cursos de licenciatura. Ainda de acordo com o autor (2000, p. 135), com a mudança no papel do professor, de especialista que possui e transmite o conhecimento para o de mediador, incentivador e orientador no processo de aprendizagem, surgem novas exigências para o profissional que vai atuar como mediador pedagógico (MASETTO, 2000).

A revolução tecnológica marcou significativamente a sociedade Ocidental a partir do último quartel do século XX, tornando-se um dos mais atuais instrumentos de 'domínio' para a nova ordem mundial. Seus efeitos têm sido refletidos em várias áreas do fazer humano, desde o mais simples comando binário, a mais complexa e avançada tecnologia da engenharia cibernética. De fato, a Era tecnológica implantou uma nova linguagem comunicacional, tornando real o mundo virtualizado, criando estereótipos de comportamentos e ressignificando o sentido de tempo e espaço, e de princípios e valores culturais entre tantos outros.

Embora as tecnologias se apresentem de forma globalizante, na tentativa de assegurar sua capacidade de reduzir diferenças, tendem a ser excludentes na filtragem de suas relações em rede, quando se percebe que nem todos os atores envolvidos se encontram com uma 'formação' situada e inclusiva nesses instrumentos, ou, que, de alguma forma em suas relações de poder, foram excluídos em suas interações, mas que independentemente dessas condições, são captados nas suas relações sociais para o mundo do consumo.

[...], a comunicação em rede transcende fronteiras, a sociedade em rede é global, é baseada em redes globais. Então, a sua lógica chega a países de todo o planeta e difunde-se através do poder integrado nas redes globais de capital, bens, serviços, comunicação, informação, ciência e tecnologia. Aquilo a que chamamos globalização é outra maneira de nos referirmos à sociedade em rede, ainda que de forma mais descritiva e menos analítica do que o conceito de sociedade em rede implica. Porém, como as redes são selectivas de acordo com os seus programas específicos, e porque conseguem, simultaneamente, comunicar e não comunicar, a sociedade em rede difunde-se por todo o mundo, mas não inclui todas as pessoas. De facto, neste início de século, ela exclui a maior parte da humanidade, embora toda a humanidade seja afectada pela sua lógica, e pelas relações de poder 
que interagem nas redes globais da organização social (CASTELLS e CARDOSO, 2006, p.17).

Todavia, não se pode negar que o desenvolvimento das novas tecnologias tem possibilitado considerável mudança na comunicação social dos últimos anos, intensificando a circulação de informação, que nem sempre se traduz em conhecimento por diferentes canais e sistemas midiáticos, como, por exemplo, o uso da internet no compartilhamento de ideias, conhecimentos e opiniões sobre vários produtos de mídia, construindo espaços interativos de novos saberes, permitindo um fluxo de participação ativa de pessoas/consumidores.

Esse processo de consumo coletivo passa a ser entendido como inteligência coletiva que segundo Jenkins (2009, p. 30) "pode ser vista como uma fonte alternativa de poder midiático. Estamos aprendendo a usar esse poder em nossas interações diárias dentro da cultura da convergência".

O sentido de convergência trabalhado pelo autor apresenta uma análise sobre as transformações tecnológicas e mercadológicas com fluxos de conteúdos através de múltiplas plataformas de mídia, em cooperação com múltiplos mercados midiáticos e com o comportamento de seu público, em busca de novas experiências de 'entretenimento'; uma concepção fundamentada em uma transformação cultural e social.

Dessa forma, a cultura da convergência dá ênfase ao movimento da cultura midiática em uma relação produção-consumo-interação, em constante movimentação e transitoriedade, com readaptação e redefinição das bases produtoras e consumidoras da cultura de mídias e comunicações, com mudanças de conceitos e novas percepções de valores.

Segundo Jenkins (2009), as mídias tradicionais geralmente passivas e as mídias atuais participativas e interativas coexistem e estão em rota de colisão, reconstruindo espaços de interação e participação, em uma convergência que reflete na mudança de paradigmas. Dessa forma, o autor apresenta em suas conclusões que:

A convergência não depende de qualquer mecanismo de distribuição específico. Em vez disso, a convergência representa uma mudança de paradigma - um deslocamento de conteúdo de mídia específico em direção a um conteúdo que flui por vários canais, em direção a uma elevada interdependência de sistemas de comunicação, em direção a múltiplos modos de acesso a conteúdos de mídia e em direção a relações cada vez mais complexas. (JENKINS, 2009, p. 325-326). 
Partindo das questões suscitadas é possível compreender por que nos últimos anos a sociedade tem passado por uma constante transformação do conhecimento midiático. Conhecimento gerado por uma cultura de consumo por produtos tecnológicos, que tem ampliado à dinâmica do mercado educacional com fortes motivações econômicas.

Essa análise sobre as transformações tecnológicas com fluxos em múltiplas plataformas, embora seja enfática diante de questões mercadológicas de consumo pessoal, imediato e midiático, também pode ser apreendida às questões do uso das tecnologias para a promoção de ambientes informatizados na educação, como ferramentas para a prática docente e para a interação dos alunos no processo de aprendizagem, fomentando o mercado de produtos e serviços no campo educacional, não se excluindo, portanto, da concepção de consumo, mas visto sob um olhar menos agressivo na sociedade capitalista.

Todas essas questões mercadológicas têm refletido em uma interatividade com as novas mídias que, a cada dia, têm ganhado espaço no campo do ensino, ampliando a dinâmica da prática docente e do processo de ensino e aprendizagem, expandindo os instrumentos da mediação pedagógica.

$\mathrm{O}$ ato de ensinar e aprender ganha novo suporte com o uso de diferentes tipos de software educacional, de pesquisa na Internet e de outras formas de trabalho pedagógico com o computador. Desse modo, é inegável que a escola de hoje precisa promover mudanças sintonizadas com esse novo contexto, a fim de garantir a apropriação crítica das novas tecnologias de informação e comunicação (NTs) disponibilizadas para o processo educacional (Grégoire et al. 1996) diante das novas possibilidades que elas descortinam (OLIVEIRA, COSTA e MOREIRA, 2001, p. 10).

Nesse sentido, compreende-se que o uso das novas tecnologias como ferramentas para a prática docente, também tem possibilitado sua convergência para a (re)construção de um espaço propício para o alargamento dos métodos e técnicas de ensino; uma concepção interacionista entre espaço-sujeito-objeto com trocas que resultam, se não expressam, uma tentativa mais autônoma pela organização e construção de saberes, tendo no professor, um mediador nessa construção. Um projeto que tem ampliado e intensificado a autonomia da prática docente, favorecendo a ações cognitivas, constituídas de práticas instrumentais que 
impulsionem o desenvolvimento do ensino em ambientes informatizados, contribuindo desse modo, para o aperfeiçoamento da aprendizagem.

\section{O USO DAS NOVAS TECNOLOGIAS DA INFORMAÇÃO E COMUNICAÇÃO E O DESAFIO DA MEDIAÇÃO PEDAGÓGICA NO ENSINO DE GEOGRAFIA}

Durante os últimos 50 anos, muitas transformações afetaram a sociedade, entre as quais as novas tecnologias da informação e da comunicação, usualmente chamadas NTIC ou TIC. Essas inovações, conforme Karsentine (2008), acrescidas às mudanças dos hábitos familiares e dos valores sociais, tiveram certamente um impacto particular nos estudantes e professores, principalmente naqueles que cresceram junto com essas transformações sociais e essa revolução tecnológica. As novas gerações ao contrário das antigas têm assim expectativas e necessidades novas, que parecem especialmente presente nos meios do ensino, tais como a universidade e a escola de educação básica.

Ultimamente, muito se tem falado sobre a utilização das Tecnologias da Informação e Comunicação (TIC) como aliadas do professor na sua prática docente (LEVY, 1998; OLIVEIRA, 2004; MORAN, MASETTO e BEHRENS, 2000; RAMAL, 2002; SAID, 1998; entre outros).

Atualmente, a meta do governo brasileiro é infiltrar as tecnologias educacionais completamente no cotidiano escolar, a Lei 9.394/96 (LDB) já cita a tecnologia nos níveis fundamental, médio e superior, como um dos pontos a serem priorizados pelos agentes educacionais. Os PCN's também já conjeturam a utilização de recursos tecnológicos no processo de ensino-aprendizagem. Os Parâmetros Curriculares Nacionais do Ensino Médio (PCNEM), também reconhecem o uso da informática na educação como uma ferramenta para novas estratégias de aprendizagem, capaz de contribuir de forma significativa para o processo de construção do conhecimento, nas diversas áreas (BRASIL, 1999).

A perspectiva de trabalhar de forma investigativa, nestes novos espaços e tempos a parti do uso das NTIC, pressupõe no professor uma mudança de atitude perante o conhecimento, significa ultrapassar a visão de prática pedagógica como simples transmissão de um conhecimento pronto e acabado que os alunos não possuem e implica outra concepção de educação, de acordo com a qual o conhecimento é visto à luz de seu processo de produção e apropriação, como produto social de contextos históricos determinados (SANTOS, GOIS e CHAVES, 2010). 
O atual estágio de desenvolvimento científico e tecnológico, que Santos (1998) denomina de período técnico-científico-informacional, requer significativas transformações nos diversos setores da sociedade, como um pressuposto natural de readaptação a uma nova realidade, cada vez mais complexa. No âmbito educacional, com ênfase na Geografia, a tecnologia vem ao encontro de novas perspectivas que visam dinamizar o processo ensino/aprendizagem, através de instrumentos interativos auxiliares.

De acordo com Pacievitch (2009, p.32), a tecnologia da informação e comunicação pode ser compreendida como:

[...] um conjunto de recursos tecnológicos, utilizados de forma integrada, com um objetivo comum. As TIC são utilizadas das mais diversas formas, na indústria (no processo de automação), no comércio (no gerenciamento, nas diversas formas de publicidade), no setor de investimentos (informação simultânea, comunicação imediata) e na educação (no processo de ensino aprendizagem, na Educação a Distância).

Complementando a noção de TIC, Ponte (2000, p.64) explica que:

[...] constituem tanto um meio fundamental de acesso à informação (Internet, bases de dados) como um instrumento de transformação da informação e de produção de nova informação (seja ela expressa através de texto, imagem, som, dados, modelos matemáticos ou documentos multimédia e hipermédia). Mas as TIC constituem ainda um meio de comunicação a distância e uma ferramenta para o trabalho colaborativo (permitindo o envio de mensagens, documentos, vídeos e software entre quaisquer dois pontos do globo). Em vez de dispensarem a interação social entre os seres humanos, estas tecnologias possibilitam o desenvolvimento de novas formas de interação, potenciando desse modo a construção de novas identidades pessoais.

Ainda explorando os vários conceitos existentes sobre as TIC, Masseto entende por novas tecnologias em educação: 
O uso da informática, do computador, da internet, do CD-ROM, da hipermídia, da multimídia, de ferramentas para educação a distância como chats, grupos ou listas de discussão, correio eletrônico etc. - e de outros recursos de linguagens digitais de que atualmente dispomos e que podem colaborar significativamente para tornar o processo de educação mais eficiente e mais eficaz. (MASETTO, 2000, p. 152)

A inserção das tecnologias de informação e comunicação no ambiente escolar, como suporte para o processo educativo, é fato que advém das transformações sofridas ao longo dos anos pela educação, no contexto da prática pedagógica. As tecnologias de informação e comunicação estão presentes em todos os setores produtivos, elas vêm inserindo-se nas instituições escolares com grande rapidez, incentivando os docentes das mais variadas modalidades a introduzirem estes recursos no processo de aprendizagem.

Mas a inclusão de tecnologias no meio educacional vem acontecendo sem que os docentes compreendam o impacto que elas causam em suas práticas educativas, ou seja, não conseguem discernir as vantagens e as desvantagens que esses recursos proporcionam para o trabalho educacional. Almeida (2001, p. 02) ressalta que com o uso da tecnologia de informação e comunicação, professores e alunos têm a possibilidade de utilizar a escrita para descrever/reescrever suas ideias, comunicar-se, trocar experiências e produzir histórias. Assim, em busca de resolver problemas do contexto, representam e divulgam o próprio pensamento, trocam informações e constroem conhecimento, num movimento de fazer, refletir e refazer, que favorece o desenvolvimento pessoal, profissional e grupal, bem como a compreensão da realidade.

Dessa maneira, é necessário que os docentes conheçam intimamente as TIC, suas reflexões em suas práticas, para que possam tomar decisões adequadas. De acordo com Oliveira (2007, p.11), a incorporação das TIC às aulas está sujeita a questões de ordem econômica e política. Por isso, conhecer a finalidade de cada uma delas, avaliando suas virtudes e limitações e as intenções que verdadeiramente estão por detrás de propostas pedagógicas que as sustentam, pode ser um dos melhores caminhos para se evitar, de um lado, uma maior exploração do trabalho docente e, de outro, uma maior perda de qualidade da educação.

Graça (2007) enumera os pontos positivos com relação à incorporação das TIC na educação, afirmando que elas proporcionam: novos objetivos para a educação que emergem 
uma sociedade de informação e da necessidade de exercer uma cidadania participativa, crítica e interveniente; novas concepções acerca da natureza dos saberes, valorizando o trabalho cooperativo; novas vivências e práticas escolares, através do desenvolvimento de interfaces entre escolas e instituições, tais como bibliotecas, museus, associações de apoio à juventude; novas investigações científicas em desenvolvimento no ensino superior, entre outros.

Analisando as assertivas acima, é concebido que as TIC proporcionam novas maneiras de interação entre professores e alunos, facilitando por meio de recursos que utilizam imagem, som e dados. Mas então, o que são recursos tecnológicos? E quais são os recursos tecnológicos mais utilizados em sala de aula?

De acordo com Geaquinto (2008, p.58), recursos tecnológicos são “[...] instrumentos que funcionam como mediadores na transmissão e/ou troca de dados entre todos os membros da comunidade acadêmica e demais envolvidos e podem ser mais ou menos sofisticados.” É através deles que o docente estimula a geração do conhecimento, utilizando a tecnologia de informação e comunicação.

Pocho, Aguiar e Sampaio (2003) classificam os recursos tecnológicos em independentes e dependentes. Os independentes são aqueles que não necessitam de aparelhos elétricos ou eletrônicos para sua produção, podemos citar como exemplo, a oratória do docente, giz, quadro-negro, cartaz, gráficos, livro didático, jornais, revistas, mural, mapas e globo terrestre. Os dependentes são as TIC propriamente ditas, são aqueles recursos que mais nos instigam, pois são modernos e interativos. Temos como exemplos: retroprojetor, TV educativa, projetor de slides, telefone, rádio, $\mathrm{CD}, \mathrm{DVD}$, computadores, softwares e celular.

Para Santiago (2006), Tecnologias Educacionais são todos os recursos que permitem enriquecer a arte de ensinar. Ao longo do tempo podemos observar que sempre se buscou uma forma de enriquecer a maneira de ensinar. Recursos como caderno, lápis, quadro negro e giz são exemplos de avanços tecnológicos incorporados no processo de ensino e aprendizagem.

Como se vê, a tecnologia não é representada somente por dispositivos eletrônicos, não é apenas o computador em conjunto com a internet, ela está presente em técnicas de baixa complexidade, que permitem o professor estabelecer relações entre os conteúdos e a vida social.

Percebe-se, cada dia com mais frequência, a adesão das escolas de uma forma mais ou menos tímida, a utilização de projetos, incluindo as tecnologias em sua proposta curricular. Esse é um dado irreversível. Observa-se, também, nas experiências que nos chegam de 
programas de formação importados de outros estados e regiões, práticas que já estão sendo utilizadas por nossos professores há algum tempo.

O professor está buscando cada vez mais sua qualificação na era tecnológica através de programas de formação que incluem a utilização das mídias, no entanto tais conhecimentos não estão sendo colocados em prática na mesma proporção em que chegaram à sociedade contemporânea. Não cabe aqui procurar culpados para justificar a má utilização da tecnologia no processo educacional.

O objetivo é que se promova um diálogo em relação ao que pode ser feito a partir dessa constatação. Portanto, para que haja uma verdadeira reforma educacional tecnológica, objetivando a melhoria do processo de ensino e aprendizagem é imprescindível que as instituições de ensino sejam as difusoras dos recursos tecnológicos, formando profissionaisusuários das tecnologias, conscientes e habilitados. Usuários, sobretudo, no exercício de sua prática profissional.

Podemos constatar que o desafio de compreender as transformações da realidade, do ponto de vista espacial, não se mostra apenas ao cidadão comum e para o ensino dos diversos componentes curriculares. Decifrar esse novo contexto tem representado, também, um grande desafio para a ciência geográfica, pois exige, fundamentalmente, pensar em novas teorias, em novos instrumentos metodológicos e em considerar atentamente a perspectiva de que a ciência é uma construção, fruto de seu tempo.

As tecnologias, dentro de um projeto inovador, facilitam o processo de ensino e aprendizagem. Sensibilizam para novos assuntos, trazem informações novas, diminuem a rotina, nos ligam com o mundo, com as outras escolas, aumentam a interação (redes eletrônicas), permitem a personalização (adaptação ao ritmo de trabalho de cada aluno) e se comunicam facilmente com o aluno, porque trazem para a sala de aula as linguagens e meios de comunicação do dia-a-dia (MORAN, MASETTO e BEHRENS, 2000).

É preciso lembrar, no entanto, que, apesar de todo o esforço na aquisição de equipamentos e programas educativos e apesar de todas as contribuições que as novas tecnologias possam trazer ao trabalho pedagógico e ao desenvolvimento do aluno, muito precisa ser feito para que resultados significativos sejam alcançados. A simples convivência com estas tecnologias nem sempre resulta em melhores desempenhos dos seus usuários. Isso significa que o trabalho com as TIC na escola deve ser bem planejado e desenvolvido de modo que só torne oportunas experiências válidas e gratificantes dos alunos. Experiências 
que, a nosso ver, devem ultrapassar um caráter meramente recreativo, ilustrativo ou, então, de uma máquina de escrever eletrônica (SANTOS e SILVEIRA, 2008).

Santos e Silveira (2008) diz que a nossa experiência no mundo atual é altamente mediada por novas tecnologias e que o ritmo dessa experiência é cada vez mais modulado pela aceleração tecnológica. Na verdade a sociedade do século XXI passa por um processo em que, a informação, a comunicação acontece de forma muito acelerada e isso ocorre devido à evolução tecnológica. O homem tem que estar preparado para receber essa nova forma de 'conhecimento'.

\section{CONSIDERAÇÕES FINAIS PARA UM NOVO RECOMEÇO}

Os avanços das novas tecnologias da informação e comunicação (NTIC) têm mudado a forma de a sociedade ver o mundo. As ações humanas movidas pelo encurtamento das distâncias e a nova concepção de tempo e espaço têm promovido uma 'revolução' de comportamentos, muitos dos quais, motivados pelo consumo.

A construção da nova realidade social que passa a emergir na sociedade Ocidental, a partir do último quartel do século $\mathrm{XX}$, consegue transmutar o sentido de imaginário, tornando real o mundo antes virtualizado.

Todas essas mudanças e transformações são perceptíveis quando passamos a olhar o mundo com outras ferramentas, com outros olhos, cujas evidências não tardam em afirmar a construção de um novo mundo - o mundo globalizado.

Olhos que refletem a crise do Estado-Nação e a coerção dos modelos paradigmáticos dos países hegemônicos, onde se busca mudar, transformando, os horizontes construídos no processo histórico de várias culturas, pela dinâmica de recriar um novo centro de equilíbrio, um centro de gravidade que força a repensar a construção dos espaços.

O espaço enquanto a mais abrangente categoria das ciências geográficas tem sido impactado por diversas reflexões epistemológicas, possibilitando ampliar as discussões sobre a interação existente entre sociedade-natureza, e toda a sua inter-relação com o fazer humano, dentre as quais, encontram-se às questões educacionais relacionadas ao uso das NTIC, favorecendo a um desenvolvimento técnico, científico e informacional utilizados como ferramenta da mediação pedagógica no ambiente da prática docente, ampliando as fronteiras da pesquisa e diversificando o processo de ensino e de aprendizagem no ensino de Geografia. 
A crise de paradigmas promovida pelas NTIC tem sido um desafio para a prática docente, onde a velha e a nova ordem/estrutura de comunicar, orientar e construir saberes se entrecruzam, convergem-se e se dissipam buscando dar sentido às transformações ocorridas na realidade da prática de ensino.

Decodificar esse novo contexto dentro da "Tirania da Circunstância" da realidade docente, termo cunhada por John Kenneth Galbraith, no livro A era da incerteza, é um grande desafio para as Ciências Geográficas, e, em particular, como instrumentos de mediação pedagógica para o professor de Geografia.

Direcionarmos nessa perspectiva, nos parece ser um provável caminho para se pensar em novos instrumentos metodológicos e novas teorias que permitam construir uma nova percepção do pensamento geográfico, sem perder a conexão de sua dinâmica e interatividade com outros saberes e ciências, mas se propondo a construir, com o uso da NTIC na prática docente, uma proposta epistemológica mais autônoma da Geografia dentro das Ciências Humanas.

\section{REFERÊNCIAS}

ALMEIDA, M. Tecnologia de informação e comunicação na escola: aprendizagem e produção da escrita. Série "Tecnologia e Currículo" - Programa Salto para o Futuro, Novembro, 2001. BRASIL. Lei de Diretrizes e Bases da Educação - lei 9394, de 20/12/96, publicada no DOU em 23/12/96.

BRASIL. Ministério da Educação, Secretaria de Educação Média e Tecnológica. Parâmetros Curriculares Nacionais: Ensino Médio. Brasília: Ministério da Educação, 1999.

BRZEZINSKI, Iria; GARRIDO, Elza. Estados da arte sobre formação de professores nos trabalhos apresentados no GT 8 da ANPEd: 1990-1998. In: REUNIÃO ANUAL DA ASSOCIAÇÃO NACIONAL DE PÓS-GRADUAÇÃO E PESQUISA EM EDUCAÇÃO - ANPEd, 22., Caxambu, 1999. Anais. Caxambu, MG, 1999. 1CD

CASTELLS, Manuel; CARDOSO, Gustavo. A sociedade em rede: do conhecimento à acção política. In: DEBATES PRESIDÊNCIA DA REPÚBLICA, 2005, Belém. Conferência. Lisboa: Imprensa Nacional - Casa da Moeda, 2006. P. 17.

CLAVAL, Paul. História da Geografia. Lisboa-Portugal: Edições 70, Lda, 2006. 
DEMO, P. Pesquisa: princípio científico e educativo. 10ed. São Paulo: Cortez, 2003.

FERREIRA, Norma Sandra de Almeida. As pesquisas denominadas "estado da arte". Educação \& Sociedade, ano XXIII, nº 79, Agosto/2002.

GEAQUINTO, Elaine Vieira Machado. Novas Tecnologias e seus efeitos no ambiente educacional. Escola Superior Aberta do Brasil - ESAB: Curso de Gestão Administrativa na Educação, Vila Velha - ES, 2008 (Monografia).

GRAÇA, Ana. Importância das TIC na sociedade actual. 2007. Disponível em: http://www.notapositiva.com/trab_estudantes/trab_estudantes/tic/10importanctic.htm\#vermai. Acesso em 08 mai. 2014.

JENKINS, Henry. Cultura da convergência. 2 ed. São Paulo: Aleph, 2009.

KARSENTI, Thierry. Impacto das TIC (Tecnologias de Informação e Comunicação) sobre a atitude, a motivação, a mudança nas práticas pedagógicas dos futuros professores. In: TARDIF, M.; LESSARD, C. O ofício de professor: história, perspectivas e desafios internacionais. $3^{\text {a }}$ ed. Petrópolis: Vozes, 2009, p. 181-199.

LÉVY, Pierre. As tecnologias da inteligência: o futuro do pensamento na era da informática. Tradução de Carlos Irineu da Costa. São Paulo. Ed. 34, 1993

A Máquina Universo - Criação, cognição e cultura informática. Porto Alegre: Artmed, 1998.

MASETTO, Marcos T. Mediação pedagógica e o uso da tecnologia. In: MORAN, José Manuel; MASETTO, Marcos T.; BEHRENS, Marilda Aparecida. Novas tecnologias e mediação pedagógica. 12 ed. Campinas: Papirus, 2000. 173p.

MORAES, Antonio Carlos Robert. Geografia: pequena história crítica. 20 ed. São Paulo: Annablume, 2005.

MORAN, José Manuel; MASETTO, Marcos T. e BEHRENS, Marilda Aparecida. Novas tecnologias e mediação pedagógica. Campinas: Papirus, 2000.

MOREIRA, Ruy. Para onde vai o pensamento geográfico?: por uma epistemologia crítica. São Paulo: Contexto, 2008.

OLIVEIRA, Maria Auxiliadora Monteiro (org.). Novas linguagens e novas tecnologias: Educação e sociabilidade. Petrópolis: Vozes, 2004.

OLIVEIRA, W. L. O docente do ensino médio $e$ as tecnologias da informação e comunicação: análise de possíveis alterações no processo de trabalho. Dissertação (Mestrado em Educação), Faculdade de Educação, Universidade Federal de Minas Gerais, 2007. 
OLIVEIRA, Celina Couto; COSTA, José Wilson da; MOREIRA, Mercia. Ambientes informatizados de aprendizagem: produção e avaliação de software educativo. Campinas: Papirus, 2001.

PACIEVITCH, Thais. Tecnologia da Informação e Comunicação. 2009. Disponível em: www.infoescola.com/informatica/tecnologia-da-informacao-ecomunicacao. Acesso em: 07 mai. 2014.

POCHO, Claudia Lopes; AGUIAR, Márcia de Medeiros; SAMPAIO, Marisa Narcizo. Tecnologia educacional: descubra suas possibilidades na sala de aula. 2.ed. Petrópolis: Vozes, 2003.

PONTE, J. P. Tecnologias de informação e comunicação na formação de professores: Que desafios? Revista Ibero-Americana de Educación, 24, 63-90. 2000. Disponível do endereço http://www.educ.fc.ul.pt/docentes/jponte. Acesso em: 07 de mai. 2014

RAMAL, Andréa Cecília. Educação na Cibercultura - Hipertextualidade, Leitura, Escrita e Aprendizagem. Porto Alegre: Artmed, 2002.

RODRIGUES, Auro de Jesus. Geografia: introdução à ciência geográfica. São Paulo: Avercamp, 2008.

SAID, Gustavo Fortes. Mídia, poder e história na era pós-moderna. Teresina: Edufpi, 1998.

SANTIAGO, Dalva Gonzalez. Novas Tecnologias e o Ensino Superior: repensando a formação docente. Dissertação de Mestrado em Educação. PUC- Campinas: 2006.

SANTOS, Francisco Kennedy S dos, GOIS, Maria Gorete de e CHAVES, Cesar Nilton Maia. Boas práticas e sucesso educacional: identificando casos bem-sucedidos nas redes públicas do estado do Ceará. FORTALEZA: SEDUC, 2010, v.1. p.172.

SANTOS, Milton. Técnica, espaço, tempo: globalização e meio técnico-científico informacional. 2. ed. São Paulo: HUCITEC, 1998.

SANTOS, Milton e SILVEIRA, Maria Laura. O BRASIL - Território e a sociedade no início do século XXI. Rio de Janeiro: Record, 2008.

THERRIEN, A.S. Trabalho docente: uma incursão no imaginário social brasileiro. São Paulo: EDUC. 1998.

VIEIRA, V. A. As tipologias, variações e características da pesquisa de marketing. Revista da FAE, Curitiba, v. 5, n. 1, p. 61-70, jan/abr. 2002. 